\title{
A Memória das Comunidades Eclesiais de Base à Luz da Psicologia da
}

\section{Libertação}

\author{
Pablo Pamplona* \\ Universidade de São Paulo - USP, São Paulo, SP, Brasil \\ ORCID: http://orcid.org/0000-0002-2744-9196 \\ Carlos Eduardo Mendes** \\ Universidade de São Paulo - USP, São Paulo, SP, Brasil \\ ORCID: https://orcid.org/0000-0002-7428-8145
}

\section{RESUMO}

A memória das lutas populares anda de par com a conscientização política da sociedade e, nesse sentido, a pesquisa com memória pode oferecer contribuições importantes para novas lutas emergentes. Neste artigo visamos discutir a relevância da reconstrução da memória política das Comunidades Eclesiais de Base (CEBs) no contexto brasileiro a partir de um desdobramento teórico de sugestões práticas feitas por Ignacio Martín-Baró. Destacamos a importância de um movimento social que emergiu das CEBs para o processo de redemocratização brasileira na década de 1980. Com aportes da Psicologia da Libertação, argumentamos que a reconstrução da memória das CEBs pode contribuir: (1) para a construção de movimentos sociais de resistência contra os recentes ataques aos direitos, oferecendo importantes lições sobre as suas formas de luta; (2) para desfazer mitos sobre a experiência das camadas populares na ditadura (1964-1985), mostrando que a resistência contra o regime militar não era exclusividade da esquerda tradicional, mas também contava com a revolta de populações periféricas; e (3) para reafirmar as virtudes populares, em particular a capacidade inventiva do povo na organização e mobilização por novas formas de relações sociais. Com isso, na linha de Martín-Baró, reivindicamos um lugar para a psicologia junto às maiorias populares.

Palavras-chave: comunidades eclesiais de base, psicologia da libertação, memória política, conscientização política, história da psicologia.

\section{The Memory of the Christian Base Communities in Light of the Liberation}

\section{Psychology}

\begin{abstract}
The memory of popular struggles goes hand in hand with society's political awareness and, in this sense, memory researches can offer important contributions to new emerging struggles. In this article, we discuss the relevance of the reconstruction of the political memory of the
\end{abstract}


Christian Base Communities (CEBs) in the brazilian context from a theoretical development of practical suggestions made by Ignacio Martín-Baró. We highlight the importance of a social movement that emerged from the CEBs for the process of brazilian redemocratization in the 1980s. With contributions from Liberation Psychology, we argue that the reconstruction of CEBs' memory can contribute: (1) to the construction of social movements of resistance against recent attacks on social and human rights, offering important lessons on their forms of struggle; (2) to dispel myths about the experience of the lower classes in brazilian dictatorship (1964-1985), showing that the resistance against the military regime was not exclusive to the traditional left, but also counted on the revolt of peripheral populations; and 3) to reaffirm the popular virtues, in particular the inventive capacity of the people in organizing and mobilizing for new forms of social relations. In line with Martín-Baró, we claim a place for psychology with the popular majorities.

Keywords: christian base communities, liberation psychology, political memory, political awareness, history of psychology.

\title{
La Memoria de las Comunidades Eclesiales de Base a la Luz de la
}

\author{
Psicología de la Liberación
}

\section{RESUMEN}

La memoria de las luchas populares camina junto a la concientización política de la sociedad $\mathrm{y}$, en este sentido, la investigación de la memoria puede ofrecer importantes contribuciones a nuevas luchas emergentes. En este artículo discutimos la relevancia de la reconstrucción de la memoria política de las Comunidades Eclesiales de Base (CEBs) en el contexto brasileño a partir de un desarrollo teórico de sugerencias prácticas hechas por Ignacio Martín-Baró. Destacamos la importancia de un movimiento social que surgió de las CEBs en el proceso de redemocratización brasileña en la década de 1980. Con aportes de la Psicología de la Liberación, sostenemos que la reconstrucción de la memoria de las CEBs puede contribuir: (1) a la construcción de movimientos sociales de resistencia contra los recientes ataques a los derechos, ofreciendo importantes lecciones sobre sus formas de lucha; (2) a disipar los mitos sobre la experiencia de las clases populares en la dictadura brasileña (1964-1985), demostrando que la resistencia contra el régimen militar no era exclusiva de la izquierda tradicional, sino que también contaba con la revuelta de las poblaciones periféricas; y 3) a reafirmar las virtudes populares, en particular la capacidad inventiva del pueblo para organizarse y movilizarse para nuevas formas de relaciones sociales. Con esto, en línea con Martín-Baró, reclamamos un lugar para la psicología con las mayorías populares.

Palabras clave: comunidades eclesiales de base, psicología de la liberación, memoria política, conciencia política, historia de la psicología.

Neste artigo discutimos a relevância da reconstrução da memória política das Comunidades Eclesiais de Base (CEBs) no contexto brasileiro a partir de um desdobramento 
teórico de sugestões práticas feitas por Ignacio Martín-Baró (1942-1989) em relação à pesquisa e o trabalho em psicologia social - particularmente, as três "tarefas urgentes" que ele sugere para a construção de uma Psicologia da Libertação (Martin-Baró, 2011). Esse objetivo se faz fortemente atraído pela força gravitacional de algumas questões preliminares importantes para qualquer reflexão que se proponha em relação às CEBs. Brustolin e Fernandes (2019) chamam a atenção para um fato fundamental - o cenário cristão brasileiro atual se caracteriza pela experiência religiosa considerada como algo individual (privatizada) sob a égide da valorização da subjetividade. Em contraponto, principalmente entre o final da década de 1960 e o início dos anos 1980, as CEBs caracterizaram um desafio à Igreja católica, em resposta à esperança de libertação dos povos latino-americanos, como analisou Frei Betto: "por meio de seus agentes pastorais, na busca por desvendar a maneira mais evangélica de tornar essa esperança uma prática eficaz de transformação da história e do mundo por vias da justiça e amor" (Betto, 1981, p. 1). A memória das lutas populares anda de par com a conscientização política da sociedade e, nesse sentido, a pesquisa com memória pode oferecer contribuições importantes para novas lutas emergentes.

A seguir, destacamos a importância de um movimento social que emergiu das CEBs para o processo de redemocratização brasileira na década de 1980. Com aportes da Psicologia da Libertação, argumentamos que a reconstrução da memória das CEBs pode contribuir: 1) para a construção de movimentos sociais de resistência contra os recentes ataques aos direitos, oferecendo importantes lições sobre as suas formas de luta; 2) para desfazer mitos sobre a experiência das camadas populares na ditadura, mostrando que a resistência contra o regime militar não era exclusividade da esquerda tradicional, mas contava também com a revolta de populações periféricas; e 3) para reafirmar as virtudes populares, em particular a capacidade inventiva do povo na organização e mobilização por novas formas de relações sociais. Com isso, na linha de Martín-Baró, reivindicamos um lugar para a psicologia junto às maiorias populares.

\section{Comunidades Eclesiais de Base: Um Breve Panorama}

As CEBs surgiram inicialmente como um projeto da Igreja católica, "em caráter experimental (...) com o intuito de amenizar o problema da carência de sacerdotes, [e] só se difundiu plenamente em meados dos anos 1960, durante o período de renovação do [Concílio] Vaticano II por estímulo da própria Igreja" (Valério, 2012, p. 168). Sua difusão teve apoio e legitimidade institucional, contando com vastos recursos humanos, financeiros e físicos. Em 
1992, uma pesquisa realizada com o suporte da Conferência Nacional dos Bispos do Brasil (CNBB), que contou com a participação de $40 \%$ das paróquias brasileiras, pôde mapear mais de 28.000 CEBs espalhadas pelo país (Valle \& Pitta, 1994). "Se repetirmos essa análise ao nível de cada Regional da CNBB, verificaremos que nenhum deles ficou mal representado. De fato, (...) em todos os regionais, a percentagem de respostas está sempre razoavelmente próxima do índice nacional (40\%)" (Valle \& Pitta, 1994, p. 11). Os resultados, portanto, são representativos para todo o território nacional. Se considerarmos os $60 \%$ de paróquias que não responderam ao questionário enviado pelos pesquisadores, podemos supor que havia, nessa época, cerca de 70 mil CEBs em território nacional; isso, quando as bases da Igreja católica já tinham migrado, em grande parte, para novos movimentos sociais que emergiram da abertura política, como o Movimento dos Trabalhadores Rurais Sem Terra (MST), ou para os núcleos de base do Partido dos Trabalhadores (PT) (Gaspar, 2010; Pinto, 2015).

Em um momento histórico em que a Igreja latino-americana se tornava cada vez mais progressista, sobretudo entre os/as defensores/as da Teologia da Libertação, essas comunidades cumpriram um papel determinante na formação de movimentos populares, mobilizados principalmente em torno de demandas relativas à região de cada CEB movimentos por creches, escolas, postos de saúde, infraestrutura nos bairros etc. É impossível dizer quantos pequenos movimentos foram formados e quantas foram as conquistas dessas milhares de comunidades. No entanto, pesquisas recentes vêm contribuindo para a reconstrução de sua memória política e nos ajudam a compreender a importância desse projeto eclesial para a abertura política do país.

Um exemplo notável é oferecido pela pesquisa de Thiago Monteiro sobre a história do Movimento do Custo de Vida (MCV), que "pode ser considerado um dos maiores movimentos populares que emergiram no contexto das lutas populares dos anos 1970 e 1980 " (Monteiro, 2017, p. 22). Diferentemente da maioria dos movimentos organizados pelas CEBs, suas demandas não diziam respeito a questões locais, mas à política econômica estabelecida pelo regime militar. Desde a sua primeira carta às autoridades escrita em 1973, as principais demandas do MCV eram o congelamento de preço de produtos de necessidade básica (em particular os alimentos) e o aumento dos salários. Em um panfleto de 1978, perguntava: "Por que os preços sobem pelo elevador e os salários sobem pela escada?” (Monteiro, 2017, p. 165, itálico do autor). Esse movimento nasceu em 1973 dos Clubes de Mães do Jardim Ângela, na zona sul de São Paulo, e se expandiu ao longo dos anos por todo o cinturão periférico da cidade. Os Clubes eram associações de mães e donas de casa, organizadas em torno das CEBs, que se reuniam para fazer oficinas de trabalhos manuais (costura, crochê, 
ponto-cruz etc.), receber palestras sobre saúde, higiene e sexualidade, e conversar sobre os problemas relativos ao bairro. A articulação entre diversos Clubes de Mães e CEBs, que se encontravam a partir de assembleias mensais, propiciou o crescimento do MCV. À medida que o movimento ganhava visibilidade, mudava suas táticas de reivindicação. Entre 1977 e 1978, no auge do movimento, coletou mais de 1,3 milhão de assinaturas - "sendo que mais de 95\% seriam provenientes dos bairros periféricos da capital paulista" (Monteiro, 2017, p. 107), justamente onde as CEBs atuavam - para cobrar suas demandas ao poder público. E, em 27 de agosto de 1978, apresentaram essas demandas para o público e a imprensa, em uma manifestação na Praça da Sé (centro de São Paulo) com mais de 20 mil pessoas, a maior parte delas vindas das periferias. Essa manifestação foi amplamente divulgada, rompendo com o silêncio ainda imposto pela ditadura e cumprindo "um papel fundamental no processo (...) de reocupar e repolitizar o espaço público (que) significou um duro golpe no projeto do regime que buscava, justamente, o controle e o esvaziamento dos espaços de participação popular" (Monteiro, 2017, p. 109).

Os recursos e a legitimidade cultural da Igreja foram fundamentais para a proliferação das CEBs, mas não explicam a vontade de suas bases pela transformação nem sua mobilização por direitos. Marco Gaspar sugere que o que propiciou essa mobilização foi "a aposta no trabalho de base, na reconstrução de formas de organização da classe desde baixo" (2010, p. 14, negrito do autor), somada ao elemento da "mística", esta composta por “elementos materiais e simbólicos que sirvam para criar vínculos e laços afetivos, identidade coletiva e sentimento de pertença a uma comunidade organizada" (Gaspar, 2010, p. 40). A memória política das CEBs evidencia a capacidade do povo de realizar manifestações massivas a partir da articulação de pequenos grupos comunitários. Também demonstra sua capacidade inventiva para a construção de novas experiências de vida, com base nos afetos e em valores presentes na religiosidade (embora ressignificados) e na cultura popular.

\section{Os Desafios da Psicologia da Libertação}

A pesquisa sobre processos de luta popular nos ajuda a desdobrar caminhos para os desafios postulados por Martín-Baró para a construção de uma psicologia envolvida com as maiorias populares. No seu texto canônico Para uma Psicologia da Libertação (Martin-Baró, 2011), ele sugere três "tarefas urgentes" para a psicologia latino-americana: a recuperação da memória histórica - que preferimos chamar aqui, seguindo a elaboração de Soraia Ansara (2005), de reconstrução da memória política -, a desideologização da experiência cotidiana e 
a potencialização das virtudes populares. A seguir, trabalharemos com cada uma dessas tarefas, procurando articular essas propostas com outros escritos de Baró e de outras/os autoras/es.

\section{Reconstruir a Memória Política}

Para Edgar Barrero Cuellar, o uso do termo "memória histórica” em Martín-Baró se opõe à "dicotomía innecesaria entre memoria e historia en la que por supuesto la historia resulta seriamente lesionada [...] al ser presentada como simple recuperadora [do passado]", enquanto a memória ganha status de autônoma, "como si la memoria social o colectiva no fuera el resultado de juegos de poder" (Cuellar, 2015, p. 29). Reafirma-se, em Martín-Baró, o caráter da "historia como posibilidad liberadora" (Cuellar, 2015, p. 30), bem como em sua crítica ao discurso dominante que "estrutura uma realidade aparentemente natural e ahistórica, que leva à sua simples aceitação" (Martín-Baró, 2011, p. 195). Walter Benjamin também denuncia essa aparência de "um presente que não é tradição, mas pára no tempo e se imobiliza" (Benjamin, 1987, p. 230), alimentada pela alienação de sua construção histórica. Em outras palavras, a ideia de um tempo "homogêneo e vazio" (Benjamin, 1987, p. 231), entendido como um encadeamento linear e cumulativo que encara o "progresso [...] como uma norma histórica" (Benjamin, 1987, p. 226), e que nos leva a crer que o que vivemos hoje é um encadeamento natural dos fatos, um caminho único que não poderia se dar de outra forma, impedindo-nos de imaginar o que está para além da realidade. Partindo dessa lógica, "é impossível tirar lições da experiência e, o que é mais importante, encontrar as raízes da própria identidade, tanto para interpretar o sentido do que atualmente se é, quanto para vislumbrar possibilidades alternativas sobre o que se pode ser" (Martín-Baró, 2011, p. 195).

O interesse de Martín-Baró pela memória é, portanto, um interesse político (Ansara, 2005, p. 25) pela construção de novos mundos. Por isso, e para nos diferenciarmos de utilizações europeias do termo "memória histórica" que não condizem com o que tratamos aqui, preferimos falar em reconstrução da memória política, como foi desenvolvido por Soraia Ansara $(2005,2008)$ a partir do próprio Martín-Baró, entre outras referências. Trata-se de um modo específico de memória coletiva, em relação dialética com processos de conscientização política: "a memória mediatiza a consciência assim como a consciência política mediatiza a memória política" (Ansara, 2005, p. 38). Na esteira da crítica de Benjamin (1987), o fazer memória aqui - e em Martín-Baró - não se dá por uma apologia do passado que pretenderia preencher espaços de forma cumulativa, como um ideal iluminista de avanço linear e 
progressivo do conhecimento que encaminharia a sociedade à superação das suas contradições. Em outro extremo, a crítica também não cai na ideologia do "passado que fica para trás”, que acusa a prática memorial de ressentimento (Gagnebin, 2014, p. 252) e, no limite, promove o apagamento dos rastros do passado, como na "solução final" dos nazistas (Gagnebin, 2006, p. 46). Ao contrário, destacar o que há de político na memória coletiva significa destacar seu espaço de disputa, em constante negociação e conflito contra a história oficial (Ansara, 2005, p. 48). No centro dessa disputa, estão os movimentos sociais: "não dá para separar a construção de uma memória política, dos grupos e movimentos sociais, pois entendemos que as construções do passado são sustentadas por estruturas coletivas" (Ansara, 2005, p. 41).

Afinal, onde está a memória das CEBs? Quem tem acesso? Ou, antes, por que interessa que sua memória, em particular, seja preservada e difundida? Fala-se de uma crise na esquerda brasileira atual e nos processos de mobilização popular por direitos (Fernandes, 2019; Gaspar, 2010). Embora alguns movimentos, como o MST, estejam empenhados no chamado "trabalho de base", as principais estratégias da esquerda continuam sendo a disputa eleitoral (Gaspar, 2010) e a "ação performática" com marchas e protestos esporádicos (Gurgel, 2017). A memória das CEBs e dos movimentos organizados à sua volta mostra uma dinâmica muito diferente, voltada para a mística e o trabalho de base (Gaspar, 2010). Suas conquistas só foram possíveis com a realização constante de uma variedade de atividades comunitárias (celebrações e novenas, oficinas de geração de renda, teatro e cinema, festas etc.), garantidas pela organização de pequenos grupos de trabalho (Betto, 1981), e com a articulação também constante entre as diversas comunidades, tanto organicamente, com assembleias por território, quanto simbolicamente, a partir da construção de um imaginário comum com base na religião e na cultura popular - vide, por exemplo, o MCV (Monteiro, 2017).

A Psicologia da Libertação visa trabalhar para, entre outras coisas, "descobrir seletivamente, mediante a memória coletiva, elementos do passado que foram eficazes para defender os interesses das classes exploradas e que voltam a ser úteis para os objetivos de luta e conscientização" (Fals Borda com citado em Martín-Baró, 2011, p. 216). O controle das narrativas sobre o passado implica em um controle das possíveis estratégias de luta no presente; seu recorte produz um estreitamento da imaginação sobre as possíveis formas que a luta pode tomar. Inversamente, a consciência política e histórica sobre a dimensão e força que as CEBs tiveram pode contribuir para a formulação de estratégias e de novas formas de organização para os movimentos populares que emergem das periferias. 
Assim, a memória das CEBs não deve servir a uma idealização saudosista de um tempo perdido, mas à identificação de elementos eficazes para a luta. Por isso nos interessa perguntar que elementos são esses. No entanto, antes de trabalhar em uma resposta possível (na terceira parte desta seção do artigo), vale destacar que, como Martín-Baró sugere, todas as perguntas com que uma pesquisa científica possa se preocupar "podem ser colocadas a partir da perspectiva de quem detém o poder social ou das maiorias populares" (Martin-Baró, 2017a, p. 76, grifo nosso). Enquanto recomenda que a psicologia se ocupe, por exemplo, com questões relativas ao sindicalismo, como: "o que leva um trabalhador a se incorporar ou não à luta sindical” (Martín-Baró, 2017a, p. 76), também alerta que essa mesma questão pode ser útil tanto para a libertação quanto para a dominação. A questão acima, por exemplo, pode servir tanto para instigar quanto para impedir a adesão a sindicatos. Da mesma forma, a reconstrução da memória das CEBs pode servir a interesses opostos à mobilização, se favorecer espaços que simulam elementos semelhantes aos das CEBs, mas que não cumprem o objetivo de luta por direitos. Por isso: "A redefinição dos problemas populares não pode ser realizada como um ato de simples boa vontade exercida no escritório do psicólogo; é um processo que exige comunicação e diálogo contínuos por parte do psicólogo e da Psicologia com as pessoas e grupos do povo" (Martín-Baró, 2017a, p. 77). As perguntas de pesquisa só respondem aos interesses do povo quando são feitas junto às organizações populares. É um desafio e uma exigência para a Psicologia da Libertação alcançar e pelo menos dialogar com essas organizações, quando não se envolver diretamente na sua luta.

\section{Desideologizar a Experiência Cotidiana}

Sabemos que o conhecimento é uma construção social. Nossos países vivem submetidos à mentira de um discurso dominante que nega, ignora ou disfarça aspectos essenciais da realidade. (...) Desideologizar significa resgatar a experiência original dos grupos e das pessoas e devolvê-las como dado objetivo, o que lhes permitirá formalizar a consciência de sua própria realidade, verificando a validade do conhecimento adquirido (Martín-Baró, 2011, p. 195-6).

Se a memória política mediatiza e é mediatizada pela conscientização política, podemos concluir que ela age necessariamente contra a ideologia - aqui compreendida no sentido marxista clássico, enquanto falsa consciência (Martín-Baró, 2017b, p. 118). A consciência sobre a realidade é diretamente afetada pela memória e só poderá ser 
compreendida no seu desenvolvimento histórico. Nesse sentido, a desideologização anda de par com a recuperação da memória; no entanto, essa "tarefa urgente" não é um simples desdobramento da anterior; e a atenção que Martín-Baró faz aqui à "experiência cotidiana" nos instiga a ultrapassar o conceito de consciência política e verificar como a pesquisa em psicologia pode afetar as ideias, sentimentos e comportamentos sobre o mundo circundante.

Aqui, a caracterização de Martín-Baró sobre o "fatalismo" latino-americano oferece um desdobramento interessante da questão. Ele parte de uma interpretação do livro Cem Anos de Solidão, de García Márquez, no qual "os acontecimentos mais extravagantes parecem normais e os anacronismos mais pitorescos adquirem um caráter de cotidianidade atemporal" (Martin-Baró, 2017c, p. 173). No desenrolar da narrativa, as estruturas de violência presentes na vida das diversas gerações de personagens, se tomam para nós formas fantásticas, para elas aparecem com um aspecto de naturalidade. "Esto es ilustrado con crudeza durante la escena en la que un cabo de la policía hace picadillos a un niño, por haberle derramado por accidente un refresco en el uniforme y, de paso, decapita al abuelo del menos, por tratar de impedirlo" (Cuellar, 2008, p. 35). Ao coronel Aureliano Buendía, que assistiu à atrocidade, resta apenas um sentimento de "extenuante impotencia" (Cuellar, 2008, p. 35). Para Martín-Baró, embora se trate de uma "novela de ficção", ela "apreende atentamente um mundo obrigado a viver de forma pseudomarginalizada em relação à história. (...) Em El Salvador, por exemplo, nada é surpreendente. Se a guerra civil que assola o país desde 1981 conseguiu algo, foi converter o insólito em cotidiano" (Martin-Baró, 2017c, p. 173-4). Para exemplificar, notadamente, ele cita alguns fatos absurdos que guardam uma bizarra semelhança com casos brasileiros atuais; por exemplo quando, em 1981, “o chefe da Polícia Nacional [de El Salvador], acusada de 'abrigar esquadrões da morte' e de sistematicamente torturar e assassinar, foi nomeado membro da Comissão de Direitos Humanos” (Martin-Baró, 2017c, p. 174).

Como no "paradoxo da dóxa" posto por Bourdieu, devemos questionar como "a ordem estabelecida, com suas relações de dominação, seus direitos e suas imunidades, seus privilégios e suas injustiças, salvo uns poucos acidentes históricos, [consegue que] perpetuese apesar de tudo tão facilmente" (Bourdieu, 2012, p. 7). Certamente não é uma qualidade natural, mas resultado de um "estreitamento forçado das possibilidades de vida" (MartínBaró, 2017c, p. 175), isto é, da restrição, pela força, das chances de intervenção no mundo. Pois bem; aqui, Martín-Baró propõe três mudanças para "eliminar" a atitude fatalista: “(a) a recuperação de sua memória histórica; (b) a organização popular; e (c) a prática de classe" (Martín-Baró, 2017c, p. 198). Ainda que já tenhamos falado sobre a primeira, retornemos a ela brevemente, a partir dessas novas reflexões, para ver como a memória das CEBs pode 
intervir na experiência cotidiana e ajudar a desvendar certos mitos desse "aparente encantamento do tempo histórico" (Martín-Baró, 2017c, p. 174).

Sua rememoração desconstrói o mito da passividade do povo brasileiro, tida como certa durante o regime militar e tratada quase como "natural" e "a-histórica", enquanto, na verdade, a história nos mostra uma efervescência de mobilizações populares pelos direitos mais básicos. Também desconstrói o mito de que a ditadura não teria problemas senão para a esquerda partidária, esta que, supostamente ressentida e/ou com fome de poder, faria uma oposição "sem fundamento" ao governo. Ao contrário, como a história do MCV nos mostra (para dar apenas um exemplo situado na cidade de São Paulo, o centro econômico do país), havia uma insatisfação massiva com a política econômica exercida pelo regime militar, especialmente entre os setores mais pobres da sociedade. Lembremos que o movimento nasceu em 1973, isto é, no último ano do chamado "milagre econômico", quando os Clubes de Mães que fundaram o MCV enviaram sua primeira carta às autoridades cobrando: "providências no sentido de resolver a caristia de vida e aumentar os salários" (Monteiro, 2017, p. 232) (sic). Lembremos também que foram mais de 1,3 milhão de assinaturas coletadas entre 1977 e 1978 (Monteiro, 2017, p. 107). De quebra, a história desse mesmo movimento nos mostra que a abertura política não partiu da boa vontade dos militares nem simplesmente de um interesse de renovação do regime pelas elites econômicas (ainda que isso seja verdade em um segundo momento, com o "movimento" pelas Diretas Já), mas, em um primeiro momento, a abertura foi potencializada pela ação de constrangimento público das elites governantes, causado pela manifestação pública de 20 mil pessoas - a maioria, mulheres periféricas - se manifestando contra a alta do custo de vida (Monteiro, 2017, p. 109).

Todos esses fatos contribuem para corrigir as mentiras difundidas sobre a ditadura, muitas delas adotadas pelo senso comum, como ajudam também a compreender a realidade social enquanto campo de conflitos históricos, atribuindo novos significados para a mobilização popular, levando a política de volta para as camadas populares e reafirmando sua capacidade humana de agência. "Essa desideologização deve se realizar, na medida do possível, em um processo de participação crítica na vida dos setores populares, o que representa uma certa ruptura com as formas predominantes de pesquisa e análise" (MartínBaró, 2011, p. 196). Por isso, mais uma vez, é destacado o lugar e papel da pesquisa: a batalha contra a mentira institucionalizada e a naturalização da injustiça vai de par com a participação nas organizações populares. 
Por fim, a rememoração de experiências bem-sucedidas de mobilização nos ajuda a descobrir dados para fomentar a organização popular "como elemento dinamizador da iniciativa dos oprimidos" e a prática de classe, no caminho para uma "ruptura dos setores populares com o círculo vicioso que produz passividade e marginalização" (Martín-Baró, 2017c, p. 199). E nos ensina, como veremos adiante, que essa prática é estimulada por fatores bastante concretos.

\section{Potencializar as Virtudes Populares}

Ainda que os movimentos contassem com uma participação importante da esquerda tradicional (Monteiro, 2017) e de setores da Igreja, as suas principais protagonistas eram mulheres "donas de casa" sem experiência política anterior. Esse protagonismo não foi simplesmente numérico; o que motivava as pessoas à luta - não apenas para se mobilizarem nas marchas e protestos, mas também para permanecerem organizadas - foi em grande parte o fator afetivo que essas mulheres imprimiram no modus operandi da luta comunitária, constituindo espaços de intimidade e acolhimento (Pamplona, 2020).

Isso era favorecido pela prática litúrgica, isto é, pela celebração religiosa feita "com sinais sensíveis, que passam necessariamente pela corporeidade da pessoa humana: a reunião com os irmãos, a saudação, o abraço, orações faladas ou cantadas, a escuta da leitura das Escrituras, o canto de salmos, hinos e cânticos, a ceia, o banho com água, a unção..." (Buyst, 1989, p. 22). Com as celebrações, as CEBs se aproximavam de pessoas sem experiência política anterior e instigavam a construção de um universo compartilhado de símbolos, ou, em outras palavras, a produção de sentido para a vida e para a luta. No entanto, mesmo entre a Igreja havia "uma tendência quase inevitável de privilegiar as leituras e comentários bíblicos levando em conta os objetivos de fomentar a discussão política”, o que formava certa "tendência racionalizadora" nas CEBs (Gaspar, 2010, p. 37) e reproduzia "uma certa tradição da cultura das organizações de esquerda de tratar tais relações primárias como algo secundário, supérfluo, e de relegá-las à esfera privada, ou seja, como uma questão do indivíduo, sobre a qual a organização não tem nada a dizer ou propor” (Gaspar, 2010, p. 39).

Essa tradição condiz com uma leitura economicista e determinista da luta de classes que Benjamin (1987) associou ao que denominava "marxismo vulgar" e que, no campo das ciências, Martín-Baró associou a um "sociologismo", que traz o perigo de "reduzir todos os problemas a variáveis sociais, até a pessoa 'não ser nada mais do que' mera expressão de forças estruturais ou sistêmicas" (Martín-Baró, 2017b, p. 125). Mas essa tradição não é 
exclusividade da esquerda nem da sociologia; antes, tem fortes raízes patriarcais (Penna, 2016, p. 238-9) e é largamente sustentada pela filosofia europeia clássica (Didi-Huberman, 2016).

Em grande medida, as CEBs rompiam com tal lógica. É particularmente ilustrativo o seguinte depoimento feito em um evento público de memória do MCV, por Amelinha Teles, na época uma militante política pelo PCdoB. Ela havia sido presa e torturada pelos militares e, depois de solta, foi para a zona sul de São Paulo se juntar ao movimento. Ela diz:

Que a gente traga, assim, esse aprendizado nosso, essa ética de fazer política, que o movimento tinha muita ética, essa fome de acolhimento! Que tinha, tinha... eu era um peixe fora d'água, né, cês tão sacando? "O que que uma feminista comunista, da luta armada, tá fazendo aqui dentro?” Né? E não, e eu tava lá, conversando com as mulheres, e sempre fui muito acolhida, por todo mundo! Eu nunca tive, eu não lembro assim, de ter tido... divergência? Pode ser, mas, assim, desentendimento não. Sempre que eu ia, eu gostava muito, ia. Gostava das mineiras, porque eu sou mineira, né gente? Adorava as mulher mineira! Porque sempre tinha uma, um canteirinho de couve ali, né, que fazia um, uma couvinha... picadinha ali com um anguzinho, né? Nossa, que coisa boa, aquilo, gente. Aquilo é bom demais! Então, eu, eu acho que isto, este tipo de movimento, nós temos que trazer pra, pro cenário político de hoje, sim. E eu acho que cê fazer política é resistir, porque, é... ali não, com todas as divergências que nós tínhamos, né, que podia ter, eu não, nós tamos ali! Que era aquele movimento, era aquele povo, era aquelas mulheres que trazem esperança pra gente. Gente, você já pensou você sair duma cadeia, dum aparato repressivo, e chegar lá num, num bairrozinho lá longe e você ser acolhida como gente, ser reconhecida como uma pessoa? Assim, uma pessoa digna? Isso é muito bom, gente! Nossa! Não tem. E nós tamos precisando disso! (Centro de Documentação e Memória da Universidade Estadual Paulista [Cedem Unesp], 2018).

A memória das CEBs demonstra a grande capacidade inventiva do povo na organização de novas formas de relações sociais, bem como a sua capacidade de superação dos problemas mais graves, pois, como Amelinha nos mostra, depois de passar pela experiência terrível da tortura, encontra "outro tipo de movimento", com uma "fome de acolhimento", onde é "reconhecida como uma pessoa digna". Martín-Baró foi um grande 
teórico da violência, dando atenção especial nos seus escritos à questão da guerra civil em El Salvador. No entanto, destaca que

"ésta no es toda la historia. Porque, junto a matanzas espantosas y actos de horroroso terrorismo, hay también continuas muestras de solidaridad así como actos de profundo altruísmo, principalmente entre aquellos que, por su condición social, carecen de poder para defenderse" (Martín-Baró, 2001, p. 299).

Ele conhecia de perto os movimentos comunitários promovidos pela Igreja no seu país; talvez por isso que, notadamente, postula como terceira "tarefa urgente" da Psicologia da Libertação "potencializar as virtudes de nossos povos", destacando "sua insubordinável solidariedade no sofrimento, sua capacidade de entrega e de sacrifício pelo bem coletivo, sua tremenda fé na capacidade humana de transformar o mundo, sua esperança em um amanhã que violentamente continua a ser negado" (Martín-Baró, 2011, p. 196). Em que pese o teor apologético desse trecho, o interesse de Martín-Baró está em buscar explicações ao fato de "o povo salvadorenho sobreviver historicamente em condições de opressão e repressão inumanas", pois, apesar da "pavorosa guerra civil que já se prolonga por mais de seis anos", algo lhe permitiu "manter viva a fé em seu destino e a esperança em seu futuro" (Martín-Baró, 2011, p. 196).

Além disso, Martín-Baró não pretende insinuar que o povo é "bom por natureza", nem ignora suas "más" qualidades, apenas não as exagera, e destaca a importância da ciência não se concentrar somente nelas. Sua apologia às virtudes está claramente voltada a um combate ao individualismo reinante tanto na sociedade capitalista quanto nas suas ciências. Assim, ele nomeia como "cosmovisión individualista" "una visión individualista del ser humano, según la cual el egoísmo, la satisfación de las necesidades y aspiraciones individuales, constituye el motor fundamental de la acción humana" (Martín-Baró, 2001, p. 300). Dessa perspectiva, "la acción socializadora, la tendencia comunitaria, la actividad altruista representarían una anormalidad" (Martín-Baró, 2001, p. 300). Daí, para citar um exemplo, um psicólogo do trabalho tão influente quanto Elton Mayo (1880-1949) considerar que "teorias gerais de socialismo, anarquismo e similares são em grande parte as construções de fantasia do neurótico" (Mayo como citado em Spink, 1996, p. 181). Ao contrário, a Psicologia da Libertação assume o desafio de considerar o altruísmo, a cooperação e a solidariedade enquanto características fundamentalmente humanas (Martín-Baró, 2001, p. 318-352). 
Como o depoimento de Amelinha Teles nos sugere, os processos do MCV, de mobilização popular e resistência contra o regime militar, só foram possíveis pela potencialização das virtudes populares, a partir de formas de organização que favorecem o cuidado e a empatia. Da mesma forma, uma atenção maior das ciências a essas virtudes pode ajudar a compreender a evolução e a possibilidade de emergência de novos processos de mobilização.

\section{Considerações Finais}

Neste artigo, buscamos articular as propostas de intervenção psicossocial postuladas por Martín-Baró com as pesquisas de memória sobre processos de mobilização popular, em geral, com foco particular na experiência das CEBs. Podemos identificar certa coerência no conjunto da obra de Martín-Baró, tanto nas suas formulações teóricas quanto nas propostas práticas de intervenção e pesquisa. Também reconhecemos uma coerência de suas propostas com aquilo que pode ser verificado da história e memória das práticas populares. A pesquisa sobre a memória das CEBs confirma a importância da recuperação da memória histórica, ajudando a reconhecer elementos perdidos ou apagados pela história oficial; oferece caminhos para a desideologização da experiência cotidiana, desfazendo mitos a respeito da ditadura e da agência do povo na sua própria história; e contribui na potencialização das virtudes populares, reconhecendo o valor dos afetos nos processos de mobilização popular.

Como apresentamos na primeira parte deste artigo, a experiência das CEBs teve uma dimensão continental e há muito ainda de sua história para ser contada, tanto no nível macro de suas formas de articulação e relação com outras organizações e instituições, quanto no micro, das experiências em cada comunidade, nas periferias ou no campo. Expomos aqui, brevemente, algumas informações históricas sobre a atuação e influência das CEBs no contexto brasileiro; sem dúvida, há muito mais para ser recuperado da memória de suas lutas, o que poderá ser feito, particularmente, no diálogo aberto com pessoas que delas participaram ativamente. Também outros processos de luta contra a opressão, do passado ou do presente, serão fontes valiosas para pesquisas futuras, que podem se beneficiar utilizando a obra de Martín-Baró para a análise. Em retorno, tais pesquisas podem oferecer importantes contribuições para as organizações populares, na medida em que o/a pesquisador/a possa se envolver com elas. 


\section{Referências}

Ansara, S. (2005). Memória política da ditadura militar e repressão no Brasil: Uma abordagem psicopolítica (Tese de doutorado). Pontifícia Universidade Católica, São Paulo, SP, Brasil. Recuperado de https://tede2.pucsp.br/bitstream/handle/17073/1/SORAIA\%20ANSARA.pdf

Ansara, S. (2008). Memória política: Construindo um novo referencial teórico na psicologia política. Revista Psicologia Política, 8(15), 31-56. Recuperado de http://pepsic.bvsalud.org/scielo.php?script=sci_arttext\&pid=S1519549X2008000100004

Benjamin, W. (1987). Sobre o conceito da história. In W. Benjamin, Magia e técnica, arte e política: Ensaios sobre literatura e história da cultura: Obras Escolhidas Vol. 1. (3a ed., pp. 222-234). São Paulo: Brasiliense.

Betto, F. (1981). O que é Comunidade Eclesial de Base. São Paulo: Abril Cultural, Brasiliense.

Bourdieu, P. (2012). A dominação masculina (11a ed.). Rio de Janeiro: Bertrand Brasil.

Brustolin, L. A., \& Fernandes, R. M. (2019). Pessoa e comunidade: Aspectos antropológicos e eclesiológicos nas reflexões pastorais da CNBB. Revista Atualidade Teológica, 23(61), 21-38. doi:10.17771/PUCRio.ATeo.37782

Buyst, I. (1989). Como Estudar Liturgia: Princípios de ciência litúrgica. São Paulo: Edições Paulinas.

Centro de Documentação e Memória da Universidade Estadual Paulista [Cedem Unesp]. (2018, Março 21). Protagonismo feminino no Movimento do Custo de Vida [Arquivo de vídeo]. Recuperado de https://youtube.com/watch?v=3iLM7B5tQC0

Cuellar, E. B. (2008). De Macondo a mancuso: Conflicto, violencia política y guerra psicológica en Colombia (Vol. 1). Bogotá: Corporación Cátedra Libre e Fundación América Nuestra.

Cuellar, E. B. (2015). Psicología de la liberación: Del discurso encantador a la práxis liberadora, Aportes para la construcción de una psicología desde el Sur. Bogotá: Ediciones Cátedra Libre. Recuperado de http://es.calameo.com/read/00442555314a3c8201dc0

Didi-Huberman, G. (2016). Que emoção! Que emoção?. São Paulo: Editora 34.

Fernandes, S. (2019). Sintomas mórbidos: A encruzilhada da esquerda brasileira. São Paulo: Autonomia Literária. 
Gaborit, M. (2011). Memória Histórica: Reverter a história a partir das vítimas. In R. S. L. Guzzo \& F. Lacerda Júnior (Orgs.), Psicologia Social para a América Latina: O resgate da Psicologia da Libertação (2a ed., pp. 245-274). Campinas, SP: Alínea.

Gagnebin, J. M. (2006). Verdade e memória do passado. In J. M. Gagnebin, Lembrar Escrever Esquecer (pp. 39-47). São Paulo: Editora 34.

Gagnebin, J. M. (2014). Esquecer o passado?. In J. M. Gagnebin, Limiar, Aura e Rememoração: Ensaios sobre Walter Benjamin (pp. 251-263). São Paulo: Editora 34.

Gaspar, M. A. F. (2010). A Falta que faz a Mística: Elementos para a retomada do trabalho de base nos movimentos populares (Tese de doutorado). Universidade de São Paulo, São Paulo, $\quad$ SP, $\quad$ Brasil. Recuperado de http://www.teses.usp.br/teses/disponiveis/47/47134/tde-30072010104834/publico/gaspar_do.pdf

Gurgel, C. (2017). Ação performática: Sintoma de uma crise na esquerda. Marx e o $\begin{array}{llll}\text { Marxismo, } & \text { 5(9), 300-321. } & \text { Recuperado }\end{array}$ http://www.niepmarx.blog.br/revistadoniep/index.php/MM/article/view/160/198

Martín-Baró, I. (2001). Acción e Ideología: Psicología Social desde Centroamérica (11a ed.). El Salvador: UCA Editores.

Martín-Baró, I. (2011). "Para uma Psicologia da Libertação”. In R. S. L. Guzzo \& F. Lacerda Júnior (Orgs.), Psicologia Social para a América Latina: O resgate da Psicologia da Libertação (2a ed., pp. 181-197) Campinas, SP: Editora Alínea.

Martín-Baró, I. (2017a). O desafio popular à Psicologia Social na América Latina. In I. Martín-Baró, Crítica e Libertação na América Latina: Estudos psicossociais (pp. 6688). Petrópolis, RJ: Vozes.

Martín-Baró, I. (2017b). Entre o indivíduo e a sociedade. In I. Martín-Baró, Crítica e Libertação na América Latina: Estudos psicossociais (pp. 101-161). Petrópolis, RJ: Vozes.

Martín-Baró, I. (2017c). O latino indolente: caráter ideológico do fatalismo latino-americano. In I. Martín-Baró, Crítica e Libertação na América Latina: Estudos psicossociais (pp. 173-203). Petrópolis, RJ: Vozes.

Monteiro, T. N. (2017). Como pode um povo vivo viver nesta carestia: O Movimento do Custo de Vida em São Paulo (1973-1982). São Paulo: Humanitas, FAPESP.

Pamplona, P. (2020). De casa em casa: afetos e mobilização popular na memória de Comunidades Eclesiais de Base (Dissertação de mestrado). Universidade de São Paulo, São Paulo, SP, Brasil. 
Penna, M. A. (2016). “À procura da comunidade perdida”: Histórias e memórias do movimento das comunidades populares (Tese de doutorado). Universidade Federal Fluminense, Niterói, RJ, Brasil. Recuperado de http://www.historia.uff.br/stricto/td/1842.pdf

Pinto, L. H. (2015). La influencia de la Comisión Pastoral de la Tierra (CPT) en la formación del Movimiento de los Trabajadores Rurales Sin Tierra (MST): Breve análisis teóricodocumental del papel de la religión en los conflictos sociales en Brasil (1954-1984). Revista de Estudios Sociales, (51), 76-88. doi:10.7440/res51.2015.06

Spink, P. K. (1996). A organização como fenômeno psicossocial: Notas para uma redefinição da psicologia do trabalho. Psicologia \& Sociedade, 8(1), 174-192. Recuperado de https://pesquisa-eaesp.fgv.br/sites/gvpesquisa.fgv.br/files/arquivos/spink__a_organizacao_como_fenomeno_psicossocial.pdf

Valério, Mairon. (2012). A historiografia da teologia da libertação na América Latina e a questão dos pares assimétricos. Fronteiras, 14(25). 161-181. Recuperado de http://ojs.ufgd.edu.br/index.php/FRONTEIRAS/article/view/1729

Valle, R., \& Pitta, M. (1994). Comunidades Eclesiais Católicas: Resultados estatísticos no Brasil. Petrópolis, RJ: Vozes, CERIS.

\section{Endereço para correspondência}

\section{Pablo Pamplona}

Rua Marselha, 811 casa 6, Jaguaré, São Paulo - SP, Brasil. CEP 05332-000

Endereço eletrônico: pablop@usp.br

\section{Carlos Eduardo Mendes}

Rua Comendador Antunes dos Santos, 831, Capão Redondo, São Paulo - SP, Brasil. CEP 05861-260

Endereço eletrônico: bentoinacio16@gmail.com

Recebido em: 30/09/2019

Reformulado em: 28/01/2020

Aceito em: 16/02/2020

\footnotetext{
Notas

* Mestre e doutorando em Psicologia Social no Instituto de Psicologia da USP.

** Doutor em Psicologia Social no Instituto de Psicologia da USP.
}

Este artigo de revista Estudos e Pesquisas em Psicologia é licenciado sob uma Licença Creative Commons Atribuição-Não Comercial 3.0 Não Adaptada. 